\title{
СИСТЕМА ОБУЧЕНИЯ СВЯЗНОМУ МОНОЛОГИЧЕСКОМУ ВЫСКАЗЫВАНИЮ НА ОСНОВЕ АКТИВНЫХ МЕТОДОВ
}

\section{CONNECTED MONOLOGICAL TEACHING SYSTEM BASED ON ACTIVE METHODS \\ N. Bolotina}

Summary: The article deals with the issues of determining the specifics of monologue speech in a foreign language and a coherent monologue statement as its product. The author develops and describes a system for teaching a coherent monologue statement based on active methods, which includes the following components: orientational-motivational, goal-setting-meaningful, procedural-technological and evaluativecorrective. Particular attention is paid to the active methods of teaching a coherent monologue statement, in particular storytelling and the project method.

Keywords: monologue speech, coherent monologue statement, teaching system for coherent monologue statement, storytelling, projects.
Болотина Наталья Ивановна

стариий преподаватель, Российский университет дружбы народов bolotina_ni@pfur.ru

Аннотация: В статье рассматриваются вопросы определения специфики монологической речи на иностранном языке и связного монологического высказывания как ее продукта. Автором разрабатывается и описывается система обучения связному монологическому высказыванию на основе активных методов, которая включает следующие компоненты: ориентировочно-мотивационный, целеполагающе-содержательный, процессуальнотехнологический и оценочно-корректировочный.

Особое внимание в статье уделяется активным методам обучения связному монологическому высказыванию, в частности сторителлингу и методу проектов.

Ключевые слова: монологическая речь, связное монологическое высказывание, система обучения связному монологическому высказыванию, сторителлинг, проекты.

Монологическая речь как феномен являлась предметом многочисленных исследований [2, с. 206-213; 3; 6, с. 149-157; 8], в которых терминологическая проблема определения ее содержательно-смыслового наполнения решалась в одном ключе: она рассматривалась в большинстве исследований как речь одного лица, выражающего в более или менее развернутой форме свои мысли.

Продуктом монологической речи, как верно полагает И.В. Рахманов [8], является связное монологическое высказывание, которое, в соответствии с коммуникативно-ориентированной парадигмой иноязычного образования, должно отвечать следующим критериям: решать определенную коммуникативную задачу: описать, рассказать, пояснить, аргументировать и т.д.; быть логичным, последовательным, завершенным, ясным; не содержать лексических, грамматических, фонетических ошибок, быть правильно оформленным в языковом отношении.

По мнению многих исследователей монологическая речь более трудна по сравнению с диалогической, поскольку требует от говорящего прочно сформированного умения выражать свои мысли в устной форме логично, последовательно и связно. В связи с этим в современной лингводидактике и методике преподавания иностранных языков ведется постоянный поиск оптимальных и эффективных методов, способов и приемов обучения монологической речи. К числу наиболее востребован- 
ных и доказавших свою эффективность относятся активные методы [7].

Обучение монологической речи на французском языке строится в рамках соответствующей системы, обеспечивающей комплексный и целостный характер данного процесса. Компонентами данной системы являются следующие:

\section{I. Ориентировочно-мотивашионный}

При реализации данного компонента системы обучающиеся получают установку на создание устного связного монологического высказывания по конкретной теме. Преподаватель может конкретизировать аспекты темы, дать смысловые и содержательные опоры, тем самым мотивируя обучающихся на монолог.

\section{II. Шелеполагаюше-содержательный}

В рамках этого компонента преподаватель сообщает обучающимся цель создания связного монологического высказывания (например, убедить кого-либо в чемлибо, представить какой-либо продукт, описать картину для туристов и т.д.), а также дает необходимый языковой материал (лексический, грамматический, страноведческий).

\section{III. Прочессуально-технологический}

При реализации данного компонента обучающиеся создают связное монологическое высказывание на французском языке, используя (если это запланировано преподавателем) опоры, к примеру, опорные фразы:

Je voudrais vous parler de la littérature. / J'aimerais vous parler de la littérature. Permettez-moi de vous parler de la littérature.

\section{IV. Оченочно-корректировочный}

В рамках данного компонента осуществляются контроль и оценивание высказывания по количественным и качественным критериям, а также намечаются способы коррекции ошибок и предотвращения их в будущем. Согласно теме исследования нас в большей мере интересует процессуально-технологический компонент, в котором могут быть представлены и реализованы активные методы обучения монологической речи. Рассмотрим некоторые из них.

Сторителлинг - это метод обучения на основе историй или через истории. В широком смысле сторителлинг подразумевает технологию, основной функцией которой выступает воздействие на слушателей через тексты увлекательных и интересных историй. В узком смысле, который интересует нас в большей мере, сторителлинг - это трансляция историй и устное повествование [1, с. 27], а история трактуется нами как интересный контент, композиционно оформленный в виде однолинейного сюжета - завязка - кульминация - развязка. Презентация историй может осуществляться преподавателем в разных форматах, к примеру, в устной форме (он сам читает / рассказывает историю или предъявляет ее в аудио- или видеозаписи); в письменной форме (в виде печатного текста); визуально (в виде презентации, инфографики, опорных схем, комиксов и т.д.); в смешанном формате (устная форма - наглядность, письменная форма - наглядность и т.д.) [4].

Методико-технологические аспекты реализации данной инновационной технологии в процессе обучения связному монологическому высказыванию на французском языке могут быть описаны в виде следующих основных этапов:

1. étape: introduction (введение новых лексических и грамматических явлений; выяснение путем постановки вопросов, что обучающиеся знают о теме предстоящего повествования; выдвижение предположений).

2. étape: présentation (предъявление истории, ответы на вопросы обучающихся, возникшие в процессе восприятия истории, развитие умений антиципации).

3. étape: discussion, des exercices (выполнение обучающимися заданий репродуктивного и продуктивного характера, связанных с продуцированием собственных историй: Discutez de l'histoire et créez la carte mentale ; trouvez la fin appropriée à l'histoire; trouvez d'autres aspects de ce sujet).

Сторителлинг как один из активных методов обучения связному монологическому высказыванию имеет большой лингвометодический потенциал, заключающийся в том, что формат повествования в виде историй способствует актуализации лексико-грамматического материала, развитию умений интерактивного взаимодействия, механизмов устной монологической речи обучающихся.

Еще одним активным методом обучения монологической речи является метод проектов [9]. Рассмотрим кратко каждый этап работы над проектом в связи с обучением монологическому высказыванию обучающихся.

Первый этап - поисковый, на котором происходит выбор темы проекта или проблемы исследования. Задача преподавателя - продумать определенные учебные ситуации для каждого обучающегося относительно его личных интересов, индивидуального потенциала и темпа усвоения материала. 
Второй этап - аналитический, во время которого согласуется единая концепция хода работы, распределяется ответственность между участниками проекта, которые обсуждают, как будут искать информацию и какие источники могут использовать. Задача преподавателя на этом этапе при формировании групп - учесть как личные симпатии обучающихся, так и возможность обмена дифференцированного опыта между участниками относительно их творческого и интеллектуального потенциала.

Далее идет практический этап, во время которого происходит оформление работы над проектом. Следующий этап - презентационный, на котором участники представляют свои проекты. Для презентации своего проекта обучающимся необходимо создать монологическое высказывание. При подготовке к выступлению участники проекта должны найти и выделить необходимую информацию, отобрать лексику по изученной теме, четко и логически выстроить речь, раскрыть решение проблемы, выразить собственное мнение - структурированно оформить свои мысли на иностранном языке.

Последний этап - контрольный, во время которого происходит оценка как результата деятельности, так и всего хода работы над проектом, степени вовлеченности обучающихся и раскрытия темы.

Метод проектов как активный метод обучения побуждает каждого обучающегося к творческой самореализации; способствует развитию интеллектуальных способностей и критического мышления; мотивирует на создание целостных монологических высказываний.

Резюмируя, следует отметить, что система обучения связному монологическому высказыванию наиболее эффективно функционирует на основе активных методов, которые предоставляют обучающимся широкие возможности для обсуждения мнений, интересные формы работы на занятиях по французскому языку, новые форматы построения монологов.

\section{ЛИТЕРАТУРА}

1. Багрецова Н.В. Сторителлинг в обучении иностранному языку: ключевые аспекты / Н.В. Багрецова // Педагогика и психология образования. - 2020.№ 2.- C. 25-38.

2. Багрова А.Я. Формирование навыков и умений монологического высказывания в средней школе - основа обучения коммуникативной компетенции на иностранном языке / А.Я. Багрова // Вестник московской международной академии. - 2017. - №1-2. - С. 206-213.

3. Гальскова Н.Д., Гез Н.И. Теория обучения иностранным языкам : учеб. пособие для студентов лингвистических университетов / Н.Д. Гальскова, Н.И. Гез. Изд. 3-е. - Москва : Издательский центр «Академия», 2006. - 205 с.

4. Ермолаев, Ж.Е., Лапухова 0.В. Сторителлинг как педагогическая техника конструирования учебных задач в вузе / Ж.Е. Ермолаева, 0.В. Лапухова // Концепт. - 2016. - № 6. - URL: http://e-kon-cept.ru/2016/16132.htm (дата обращения: 24.09.2021).

5. Коряковцева Н.Ф. Продуктивное языковое образование как реализация развивающей образовательной парадигмы / Н.Ф. Коряковцева // Иностранные языки в школе. - № 2. - 2018. - С. 2-10.

6. Назарова А.В. Особенности иноязычной монологической речи и система ее оценивания / А.В. Назарова // Вестник Пермского государственного гуманитарно-педагогического университета. - 2016. - Серия № 1. - С. 149-157.

7. Панфилова А.П. Инновационные педагогические технологии : Активное обучение : учеб. пособие для студ. высш. учеб. заведений / А.П. Панфилова. Москва : Издательский центр «Академия», 2009. - 192 с.

8. Рахманов,И.В. Обучение устной речи на иностранном языке / И.В. Рахманов. - М.: «Просвещение», 2009. - 160 с.

9. Хабибулина Э.А. Метод проектов как способ развития монологической речи (на примере английского языка) / Э.А. Хабибулина, К.В. Беседина // сборник

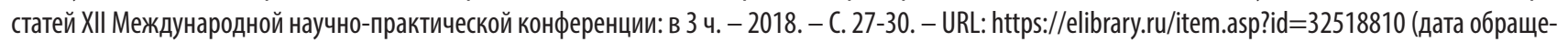
ния: 24.09.2021).

(с) Болотина Наталья Ивановна (bolotina_ni@pfur.ru).

Журнал «Современная наука: актуальные проблемы теории и практики» 